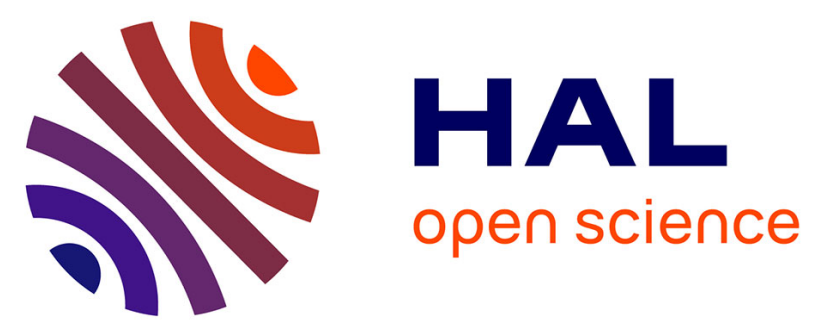

\title{
Modelling and control of a multi phase induction system for metal disc heating
}

Majid Souley, Julie Egalon, Stéphane Caux, Olivier Pateau, Pascal Maussion

\section{To cite this version:}

Majid Souley, Julie Egalon, Stéphane Caux, Olivier Pateau, Pascal Maussion. Modelling and control of a multi phase induction system for metal disc heating. IECON 2010 - 36th Annual Conference on IEEE Industrial Electronics Society, Nov 2010, Phoenix, United States. pp.562-567. hal-01222180

\section{HAL Id: hal-01222180 \\ https://hal.science/hal-01222180}

Submitted on 29 Oct 2015

HAL is a multi-disciplinary open access archive for the deposit and dissemination of scientific research documents, whether they are published or not. The documents may come from teaching and research institutions in France or abroad, or from public or private research centers.
L'archive ouverte pluridisciplinaire HAL, est destinée au dépôt et à la diffusion de documents scientifiques de niveau recherche, publiés ou non, émanant des établissements d'enseignement et de recherche français ou étrangers, des laboratoires publics ou privés. 


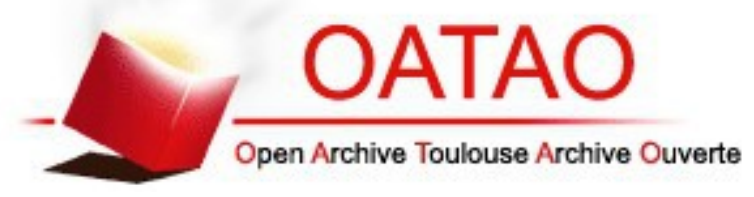

\section{Open Archive TOULOUSE Archive Ouverte (OATAO)}

OATAO is an open access repository that collects the work of Toulouse researchers and makes it freely available over the web where possible.

This is an author-deposited version published in : http://oatao.univ-toulouse.fr/ Eprints ID : 14324

To link to this article : DOI: $10.1109 /$ IECON.2010.5675223

URL : http://dx.doi.org/10.1109/IECON.2010.5675223

To cite this version : Souley, Majid and Egalon, Julie and Caux, Stéphane and Pateau, Olivier and Maussion, Pascal Modelling and control of a multi phase induction system for metal disc heating. (2010) In: IECON 2010 - 36th Annual Conference on IEEE Industrial Electronics Society, 7 November 2010 - 10 November 2010 (Phoenix, United States).

Any correspondance concerning this service should be sent to the repository administrator: staff-oatao@listes-diff.inp-toulouse.fr 


\title{
Modelling and control of a multi phase induction system for metal disc heating
}

\author{
Souley M. ${ }^{1,2,3}$, Egalon J. ${ }^{1,2}$, Caux S. ${ }^{1,2}$, Pateau O., Maussion P. ${ }^{1,2}$ \\ ${ }^{1}$ Université de Toulouse ; INPT, UPS ; LAPLACE (Laboratoire Plasma et Conversion d'Energie) ; ENSEEIHT, 2 rue Charles \\ Camichel, BP 7122, F-31071 Toulouse cedex 7, France. \\ ${ }^{2}$ CNRS; LAPLACE; F-31071 Toulouse, France \\ ${ }^{3}$ EDF R\&D, Eco-efficiency \& Industrial processes Dept, F-77250, Moret sur Loing, France
}

\begin{abstract}
This paper presents the study of a multi-phase induction system for metal disc heating. It proposes a complete electrical and thermal modelling of the whole system in PSim software, with a reduced simulation time. An optimisation procedure allows us to calculate the optimal parameters for calibrating the system in order to obtain a uniform heating of the work piece. This was possible from the knowldege of the current density distribution extracted from the finite element software Flux2D and from the impedance matrix that describes the electrical behaviour of the three coils suuplied by current source inverters. This studies also concern a first simple current control method. As a result, the experimental thermal distributions are in good agreement with simulated ones.
\end{abstract}

\section{INTRODUCTION}

In comparison with other heating solutions, induction heating offers a lot of advantages, such as fast and exact heating with high power density, many control possibilities with the help of power electronic. The operation of induction heating devices has to face many problems that cannot be fully and easily characterized by a mathematical formulation. Indeed, interactions between the converter, the inductor and the work piece to be heated, make the system complex, but it is possible to separate these difficulties by discerning the two main parts that constitute an induction heating system $[1,2]$. In order to improve the tuning facility and the flexibly, it might be associated with an optimal control. But it requires first a good representation that allows calibrating the whole system. Induction heating systems are divided into two parts, the power supply and the inductors. Few softwares allow magneto thermal studies such as Flux $2 \mathrm{D} \otimes$, moreover they are complex and time consuming [3,4]. To overcome these drawbacks, a model of the complete system was developed with [7], including the load thermal behaviour, power inductors, switches and RMS control of the inductor currents. The proposed simplified model relates to 3 phases transverse flux induction heating. We successively present the electrical model, the thermal model, the control scheme, the simulation and experimental results we obtained and their improvements.

\section{SYSTEM MODELLING: ELECTRICAL PART}

The system consists of three inductor coils (Fig.1 \& Fig2) organized face to face in a transverse flux configuration and a disk plate i.e. the load to be heated. This system can be represented by a 4 phase electrical circuit including the material to be heated (index 4), which is subject to a current flow according to the induction heating principle, but with zero voltage.

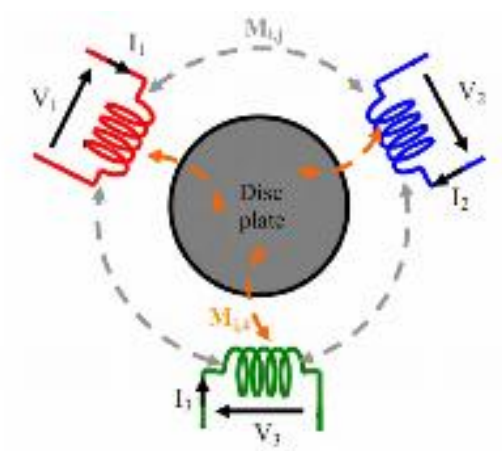

Fig. 1. Coils and work piece coupling
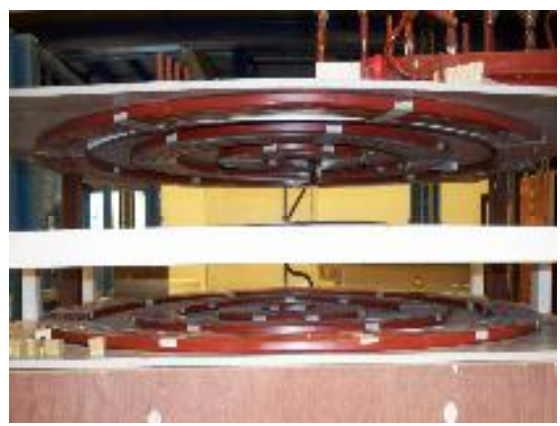

Fig. 2. Induction heating device coils

Equation 1 provides a matricidal description of the system when the three coils are fed by currents $I_{1}, I_{2}$ an $I_{3}$ while $I_{4}$ is the current flowing through the material to be heated.

$\left[\begin{array}{c}\overline{\mathrm{V}}_{1} \\ \overline{\mathrm{V}}_{2} \\ \overline{\mathrm{V}}_{3} \\ \overline{\mathrm{V}}_{4}=0\end{array}\right]=\left[\begin{array}{cccc}\mathrm{R}_{1}+\mathrm{j} \mathrm{M}_{1} \omega & \mathrm{j} \mathrm{M}_{12} \omega & \mathrm{j} \mathrm{M}_{13} \omega & \mathrm{jM} \omega \\ \mathrm{j} \mathrm{M}_{21} \omega & \mathrm{R}_{2}+\mathrm{j} \mathrm{M}_{2} & \mathrm{j} \mathrm{M}_{23} \omega & \mathrm{j} \mathrm{M}_{24} \omega \\ \mathrm{j} \mathrm{M}_{31} \omega & \mathrm{j} \mathrm{M}_{32} \omega & \mathrm{R}_{3}+\mathrm{j} \mathrm{M}_{3} \omega & \mathrm{j} \mathrm{M}_{34} \omega \\ \mathrm{j} \mathrm{M}_{41} \omega & \mathrm{j} \mathrm{M}_{42} \omega & \mathrm{jM}_{43} \omega & \mathrm{R}_{4}+\mathrm{j} \mathrm{M}_{4} \omega\end{array}\right]\left[\begin{array}{c}\overline{\mathrm{I}}_{1} \\ \overline{\mathrm{I}}_{2} \\ \overline{\mathrm{I}}_{3} \\ \overline{\mathrm{I}}_{4}\end{array}\right]$

- $\mathrm{M}_{\mathrm{i}, 4}$ : coupling terms between the inductors $\mathrm{i}$ and the material to be heated (load) 
- $R_{i}, L_{i}$ : self resistance and inductance for inductor $i$

- $\mathrm{R}_{4}$ and $\mathrm{L}_{4}$ : resistance and inductance for the disk plate

- $\mathrm{M}_{\mathrm{ij}}$ : mutual inductance between inductor $\mathrm{i}$ and $\mathrm{j}$.

From the 4th line, it comes:

$$
\overline{\mathrm{I}}_{4}=-\mathrm{j} \cdot \frac{\omega \mathrm{M}_{41} \cdot \overline{\mathrm{I}}_{1}+\omega \mathrm{M}_{42} \cdot \overline{\mathrm{I}}_{2}+\omega \mathrm{M}_{43} \cdot \overline{\mathrm{I}}_{3}}{\left(\mathrm{R}_{4}+\mathrm{j} \omega \mathrm{L}_{4}\right)}
$$

which leads to a reduced $3 \times 3$ relationship, between [V] and [I] with

$$
\bar{Z}=\left[\begin{array}{lll}
\bar{Z}_{11} & \bar{Z}_{12} & \bar{Z}_{13} \\
\bar{Z}_{21} & \bar{Z}_{22} & \bar{Z}_{23} \\
\bar{Z}_{31} & \bar{Z}_{32} & \bar{Z}_{33}
\end{array}\right]
$$

$\bar{Z}_{i, i}=\left(R_{i}+\frac{\omega^{2} M_{i, 4}^{2} \cdot R_{4}}{R^{2}{ }_{4}+\left(L_{4} \omega\right)^{2}}\right)+j \omega\left(L_{i}-\frac{L_{4} \cdot M_{i, 4}^{2} \omega^{2}}{R^{2}{ }_{4}+\left(L_{4} \omega\right)^{2}}\right)$

$\bar{Z}_{i, j}=\left(\frac{\omega^{2} M_{i, 4} \cdot M_{4, j} \cdot R_{4}}{R^{2}{ }_{4}+\left(L_{4} \omega\right)^{2}}\right)+j \omega\left(M_{i, j}-\frac{L_{4} M_{i, 4} \cdot M_{4, j} \cdot \omega^{2}}{R^{2}{ }_{4}+\left(L_{4} \omega\right)^{2}}\right)$

From (4) and (5), we can see that the presence of the material to be heated increases the resistance of the diagonal terms and creates a mutual resistance in impedance coupling terms. Of course it is possible to run numerical simulations on dedicated software such as Flux 2D, Flux 3D or Inca 3D. In fact, these simulations are highly time consuming (3 weeks for a given configuration) and as the inductors and the bus-bar have a particular form, it is often not possible to fully represent them in these programs. Consequently, measurements will be necessary to obtain the real and imaginary parts of the impedances including the coupling terms. The different terms given in (6) calculated according to a "pseudo-energy" method from V and I measurements, details are given in [5].

$$
\left[\begin{array}{ccc}
33.1+j .24466 & 25.96+j .43 .77 & 21.48+j .24 .33 \\
25.83+j .43 .61 & 67.31+j 247.32 & 65.93+j .11366 \\
20.86+j .21 .39 & 65.22+j .111 .39 & 107.11+j .56820
\end{array}\right] m \Omega(6)
$$
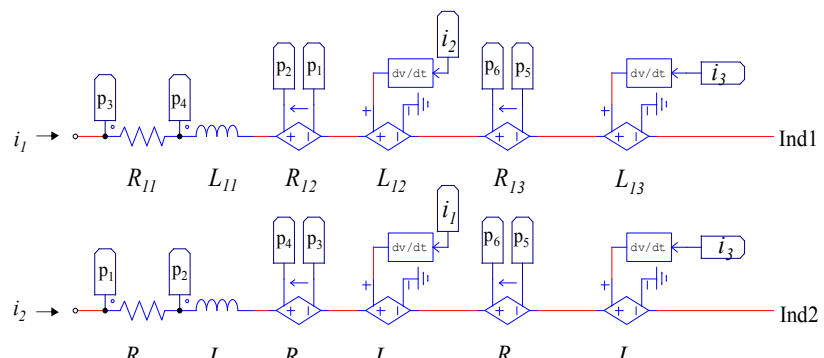

$$
\begin{array}{lllll}
R_{22} & L_{22} & R_{21} & L_{21}
\end{array} R_{23} \quad L_{23}
$$

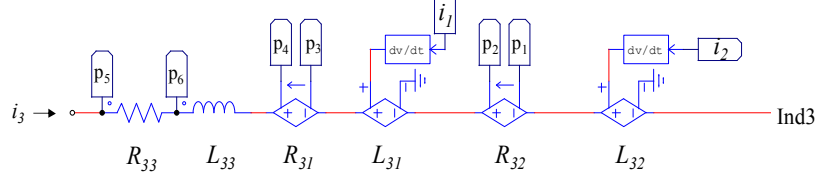

Fig. 3. Electrical model of the coupled inductors

Fig. 3 describes the arrangement of current-controlled voltage sources and passive components used to simulate the matricidal model (1), including the dissymmetry between $Z_{12}$ and $Z_{21}$ for example. For example on phase 1, R11 and L11 represent the self resistance and inductance while the other terms are the coupling effects, i.e. $\overline{Z_{12}} * \overline{I_{2}}$ and $\overline{Z_{13}} * \overline{I_{3}}$ respectively.

\footnotetext{
Fig. 4. Current source and inverters
} 
The whole system is supplied by a set of current source inverters and a controlled current source, as depicted in Fig. 4. It is important to notice that power electronics does not work according to PWM principles but with only one pulse per half-period, consequently, the control loops will have to adjust the duty cycle [6] on each phase.

Fig. 5 shows for phases 1 and 2, the inverter current waveform and the current in the corresponding inductor. The specific angles derive from an optimization procedure of the heat profile in the plate that is described in [1]. Due to the LC resonant circuit on each phase, the inductor currents are quite sinusoidal despite square wave supply inverter currents, as it can be seen in figures 6 and 7 .

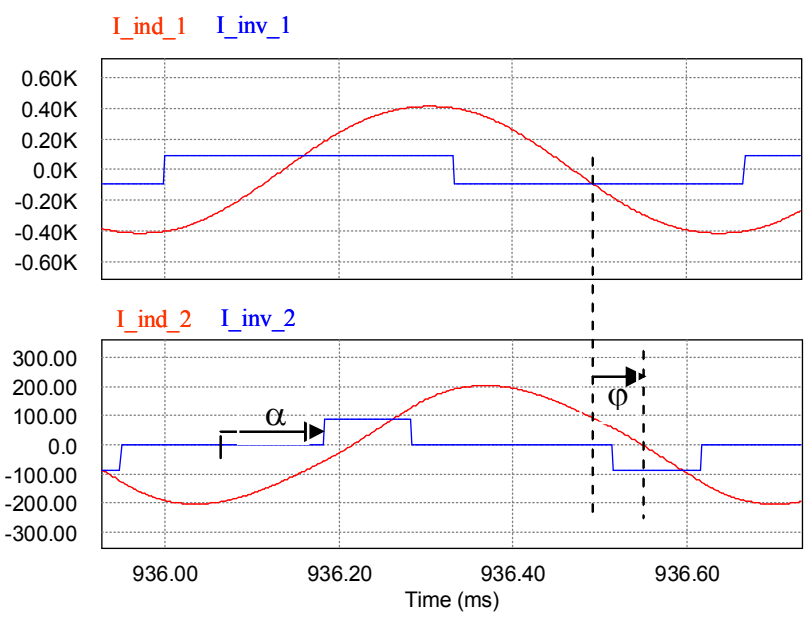

Fig. 5. Inverter and inductor waveforms pour phase 1 and 2

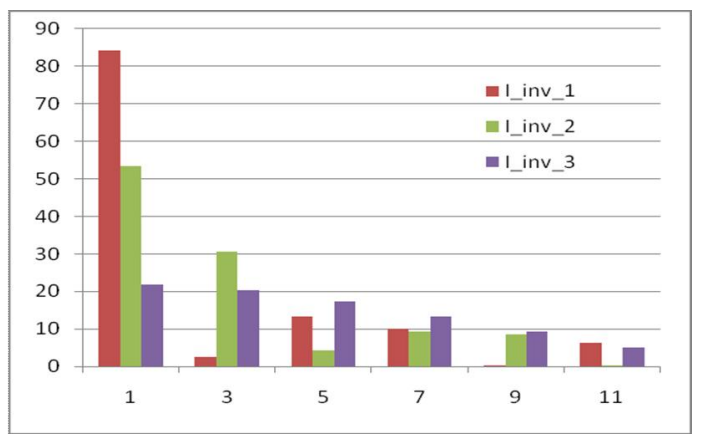

Fig. 6. FFT for inverter currents with $\alpha_{1}=30^{\circ}$

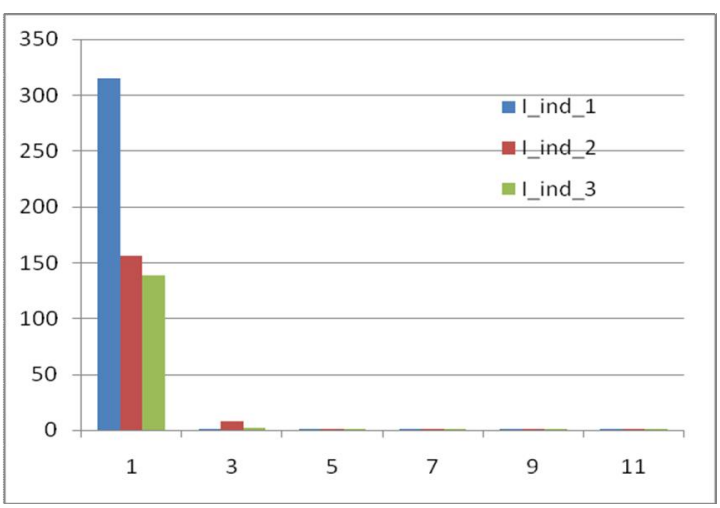

Fig. 7. FFT for inductor currents
A particular attention should be paid to the capacitor values. The theoretical calculation leads to $[\mathrm{C} 1, \mathrm{C} 2, \mathrm{C} 3]=[388.4$; $217.9 ; 133.6](\mu \mathrm{F})$ which are implemented as $[\mathrm{C} 1, \mathrm{C} 2, \mathrm{C} 3]=$ $[387 ; 221 ; 136](\mu \mathrm{F})$ taking into account only normalized capacitances. The first experimental results in Fig. 9 are not satisfying as the phase lag $\varphi_{21}$ between currents $I_{1}$ and $I_{2}$ is $52.3^{\circ}$ instead of $39.9^{\circ}$ and $57^{\circ}$ instead of $45.3^{\circ}$ for $\varphi_{31}$ between currents $I_{1}$ and $I_{3}$. This phenomenon is mainly due to parametric dispersion on the capacitor values. Fig. 8 shows an example of the capacitor parametric characterization that had to be done. For example, the practical capacitance value of the biggest capacitor was $43 \mu \mathrm{F}$ instead of $47 \mu \mathrm{F}$.

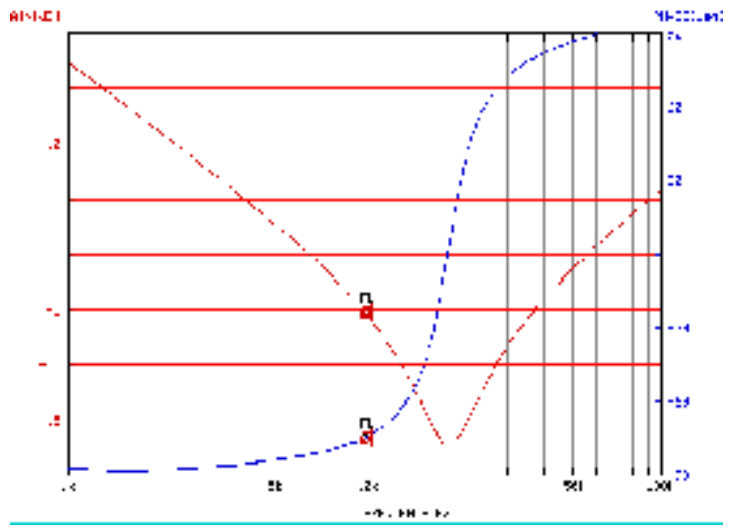

Fig. 8. Impedance diagram for a $47 \mu \mathrm{F}$ capacitor

A $33 \mu \mathrm{F}$ capacitor is added on the first bank and the result is described in Fig. 9 where the phase shifts are closer from their references than before.

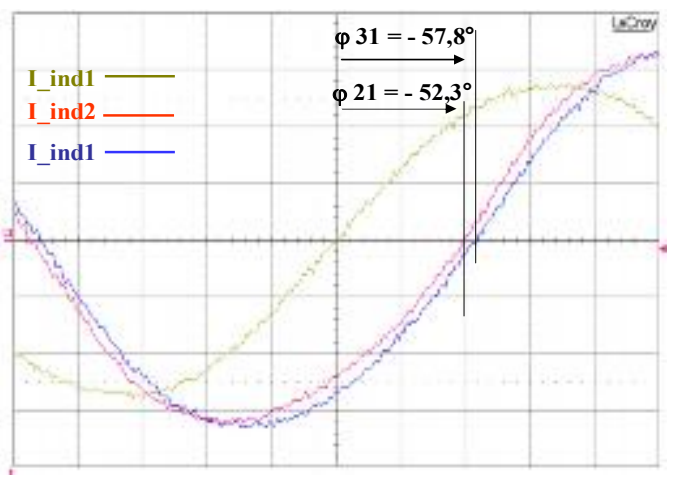

Fig. 9. Standard current phase shifts

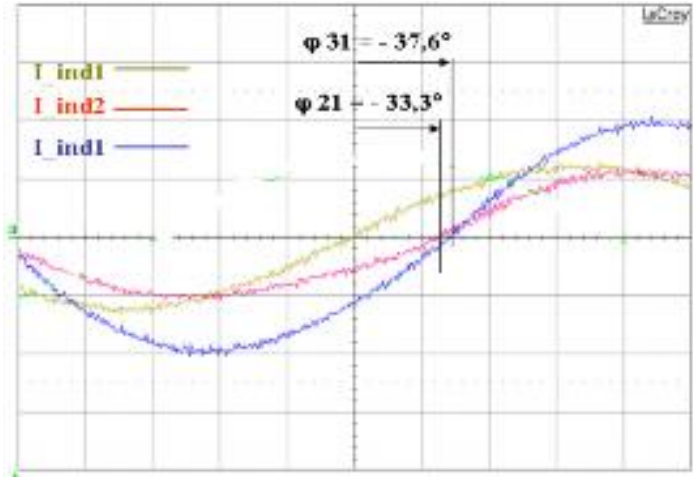

Fig. 10. Current phase shifts with an additional capacitor of $33 \mu \mathrm{F}$ on bank 1 
The phase shift sensitivity versus capacitor values must be studied in order to confirm the origin of the phase errors in Fig. 10. Equations (7) come from the circuit in Fig. 4 and from the matricidal model (1), where $\mathrm{I}_{\text {inv1 }_{\mathrm{f}}}$ is the fundamental of the inverter current on phase 1 .

$$
\begin{aligned}
& \bar{I}_{i n v 1 f}=\frac{\left(\bar{Z}_{11}+\bar{Z} c_{1}\right) \bar{I}_{1}+\bar{Z}_{12} \bar{I}_{2}+\bar{Z}_{13} \bar{I}_{3}}{\bar{Z}_{c_{1}}} \\
& \bar{I}_{i n v 2} f=\frac{\left(\bar{Z}_{22}+\bar{Z} c_{2}\right) \bar{I}_{2}+\bar{Z}_{21} \bar{I}_{1}+\bar{Z}_{23} \bar{I}_{3}}{\bar{Z}_{c_{2}}} \\
& \bar{I}_{i n v 3} f=\frac{\left(\bar{Z}_{33}+\bar{Z} c_{3}\right) \bar{I}_{3}+\bar{Z}_{31} \bar{I}_{1}+\bar{Z}_{32} \bar{I}_{2}}{\bar{Z} c_{3}}
\end{aligned}
$$

These currents can be expressed in (8) from the knowledge of the duty cycle and the shift angles for $\mathrm{I}_{\text {inv }} \mathrm{i}$ such as represented on Fig 5. Because of the resonant circuit, only the fundamental of the currents will be taken into account, leading to analytic expressions of the inductor currents (9) in relationship with the circuit parameters and especially with the capacitor values.

$$
\begin{gathered}
I_{\text {inv }-i}=I_{S} \cos \left(\alpha_{i}\right) \\
\bar{I}_{1}=F_{1}\left(C_{1}, C_{2}, C_{3}, I_{\text {ond } 1} f, I_{\text {ond } 2} f, I_{\text {ond } 3} f, \bar{Z}\right) \\
\bar{I}_{2}=F_{2}\left(C_{1}, C_{2}, C_{3}, I_{\text {ond } 1} f, I_{\text {ond } 2} f, I_{\text {ond } 3} f, \bar{Z}\right) \\
\bar{I}_{3}=F_{3}\left(C_{1}, C_{2}, C_{3}, I_{\text {ond } 1} f, I_{\text {ond }_{2}} f, I_{\text {ond } 3} f, \bar{Z}\right)
\end{gathered}
$$

Then, the variations of the phase shifts between the inductor currents can be plotted in Fig. 11.

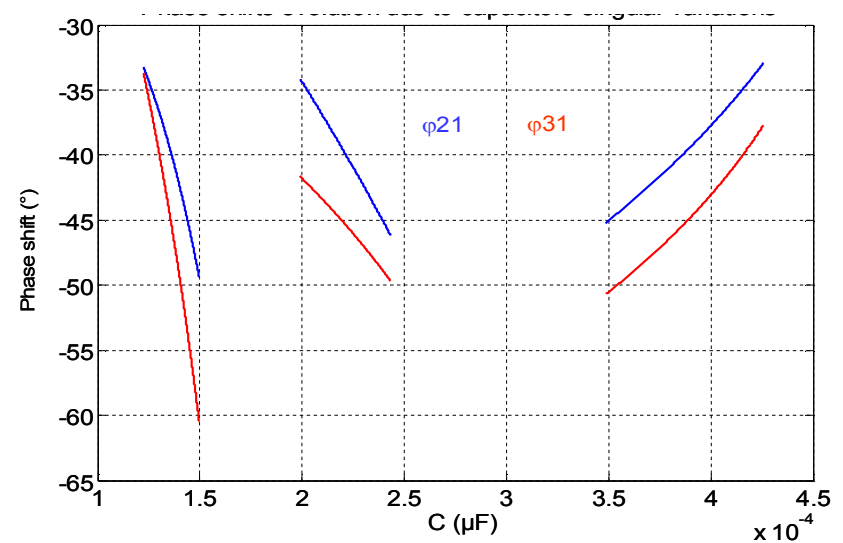

Fig. 11. Phase shift sensitivity versus separate capacitor variations

Moreover, the phase shifts due to the individual capacitor variations are almost linear and can be added. The global phase shift variation is almost equal to the sum of the phase shifts due to separate variations, as it can be seen in Fig. 12 if they are limited within a reduced variation domain around the nominal values.

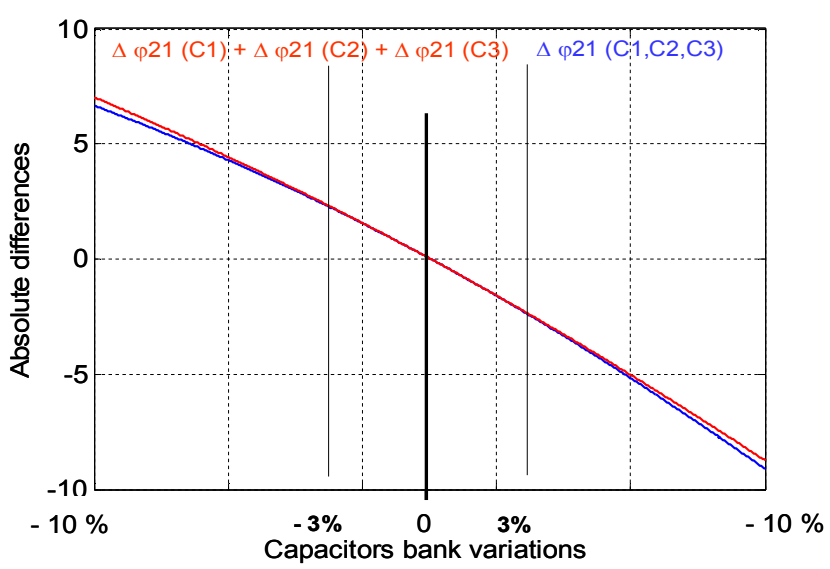

Fig. 12. Phase shift sensitivity versus global capacitor variations

Moreover, a frequency analysis, see Fig.13 can be computed in order to highlight the current transfer ratio between the inverter currents and the inductor currents, in magnitude and phase, when the working frequency is subject to variations. For example, it can be noticed on the magnitude plot, that the resonant filter is rather selective, has an increasing effect at the nominal frequency and attenuates the other frequency components.

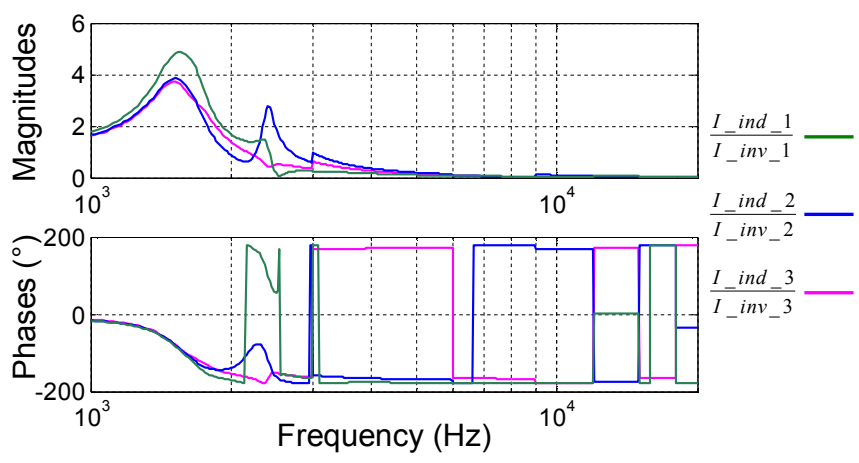

Fig. 13. Bode plots of the currents transfer ratio and phase

\section{SYSTEM MODELLING: THERMAL PART}

The temperature is usually obtained by solving the heat equation which takes into account either convection, conduction in the material or radiation effects. The complete thermal model which is fully described in [7], is based on the non linear power density distribution created in the plate by the 3 phases [3]. In practice it is impossible to measure the induced currents in the work piece but an image of their distribution in the material at each abscissa along the radius can be obtained in Flux2D® software. Under the hypothesis that the temperatures around the thermal measurement points (thermocouples) are uniform as well as the resistivity $\rho_{\text {disc }}$ around the considered points, the power density is given by (14).

$$
D p_{(R i)}=\rho_{\text {disc }} . J_{\text {disc }}^{2}\left(R_{i}\right)
$$


$J_{\text {disc }}$ represents the total induced currents in the material at any point $\mathrm{i}$ along the radius when $\rho_{\mathrm{disc}}$ is the resistivity. Fig. 14 and Fig. 15 show an example of the induced current distribution extracted from Flux $2 \mathrm{D}{ }^{\circledR}$ under condition of $20^{\circ} \mathrm{C}$ at $1500 \mathrm{~Hz}$.

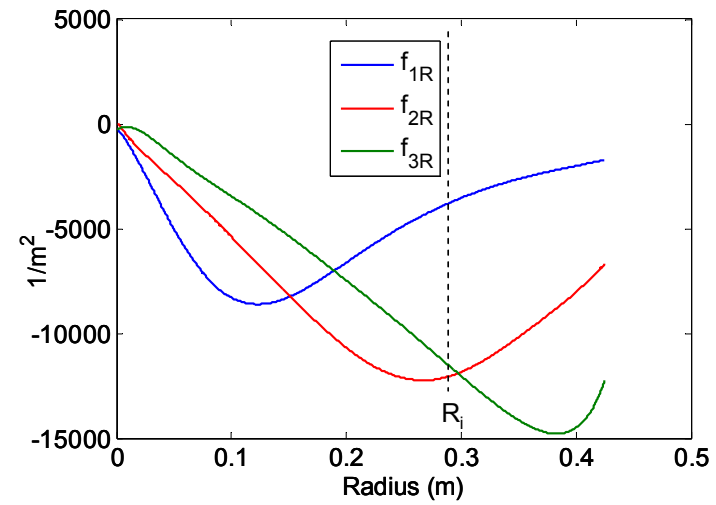

Fig. 14. Real part of induced current at $1500 \mathrm{~Hz}$ under ambient temperature of $20^{\circ} \mathrm{C}$

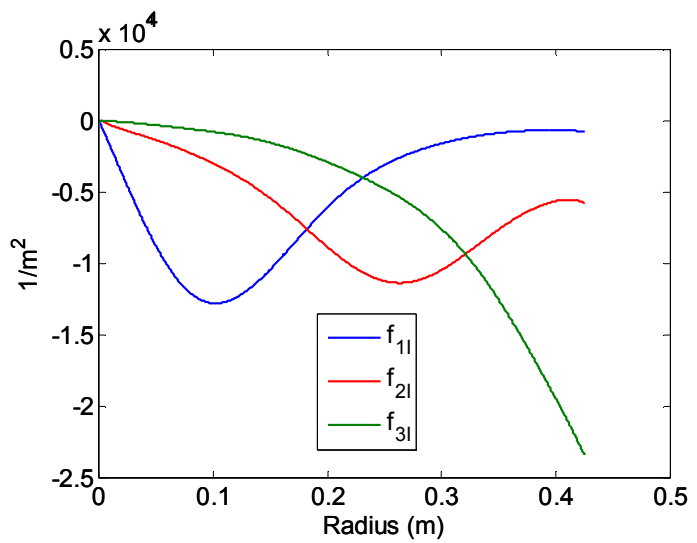

Fig. 15. Imaginary part of induced current at $1500 \mathrm{~Hz}$ under ambient temperature of $20^{\circ} \mathrm{C}$

The following formula shows the calculation of induced currents that uses the features of induced current distribution images in Fig. 3 and the real and imaginary parts of current injected in the inductors.

$$
\begin{aligned}
J_{d i s c}\left(R_{i}\right) & =\sum_{k=1}^{3}\left(f_{k R}\left(R_{i}\right) I_{k R}-f_{k I}\left(R_{i}\right) I_{k I}\right) \\
& +j \cdot \sum_{k=1}^{3}\left(f_{k R}\left(R_{i}\right) I_{k I}+f_{k I}\left(R_{i}\right) I_{k R}\right)
\end{aligned}
$$

where

- $\quad f_{K R}(R i)$ is the real part of the image of induced distribution current at the abscissa $R_{i}$,

- $\quad f_{K I}(R i)$ is the imaginary part of the image of induced distribution current at the abscissa $\mathrm{R}_{\mathrm{i}}$,

- $\quad I_{k R}$ : real part of the current $\mathrm{I}_{\mathrm{k}}$,

- $\quad I_{k I}$ : imaginary part of the current $\mathrm{I}_{\mathrm{k}}$

Ten measurement points by thermocouples $\left(R_{1}\right.$ to $\left.R_{10}\right)$ along the radius of the disc plate are considered. The values of the different induced current images, for the real part and the imaginary part, are red at each measurement point, such as for
$0.27 \mathrm{~m}$ in Fig. 14. The, the temperature model derives from (11).

$$
D_{p}\left(R_{i}\right)=\rho . c \frac{d \theta_{i}}{d t}+\frac{2 h}{e}\left(\theta_{i}-\theta_{a}\right)
$$

\section{CURRENT CONTROL}

As far as we know, very few works have been done for the control of this kind of coupled system [8], [9]. As a first step in our study, a simplified control scheme is proposed hereafter. According to figure 16 which describes it for one phase, it includes a PI controller, a limiter, a cosine inverse function block that leads to the firing angle of the corresponding inverter. Besides, the current is sensed and converter into its RMS value with the help of a square function, a low-pass filter with $600 \mathrm{~Hz}$ as the cut-off frequency and a square root function.

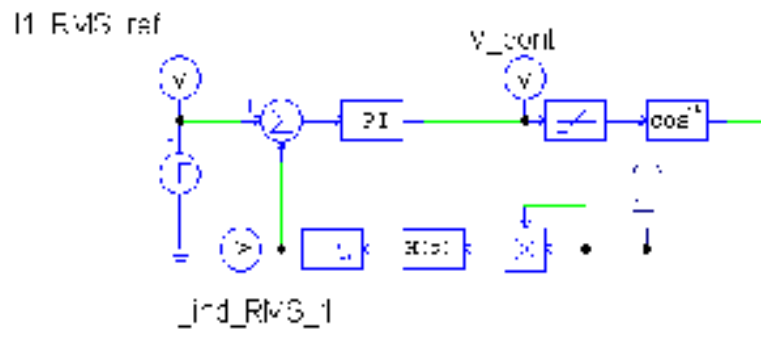

Fig 16. Current control scheme

The PI controller is tuned according to pole placement method, the closed-loop bandwidth is set to $600 \mathrm{~Hz}(<1500$ $\mathrm{Hz})$ as in open-loop. Fig. 17 shows the transient from 0 to steady state on the inverter currents and on the inductor currents. The reference RMS values are reached within few supply periods.
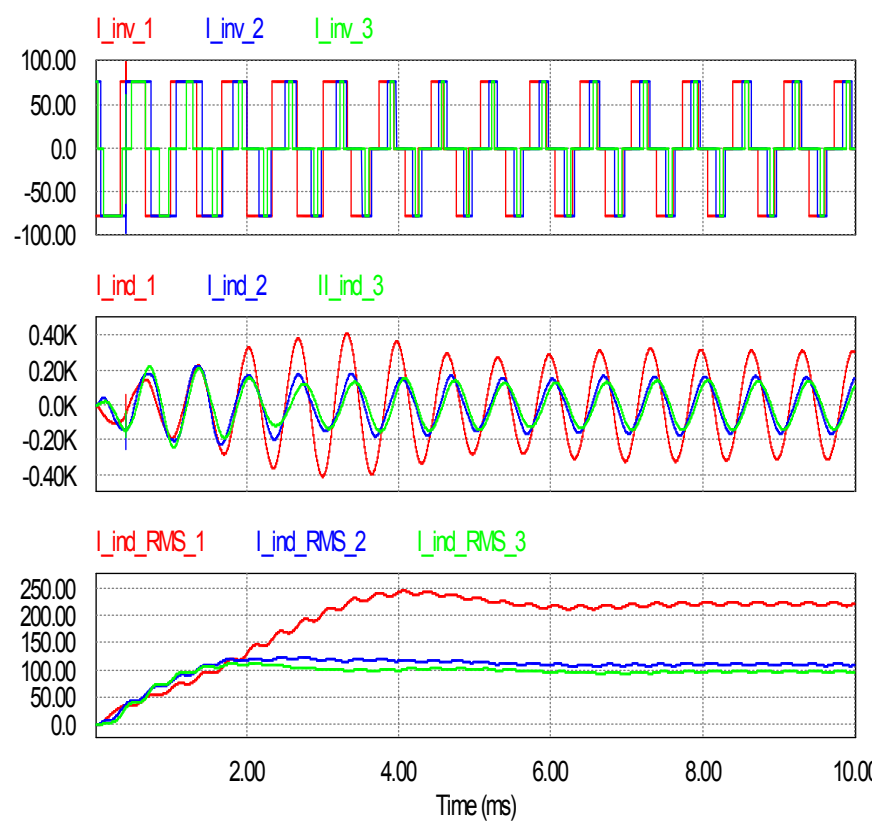

Fig. 17. Inverter and inductor current waveforms from 0 to steady state 
The steady state duty cycles depend on the source current value. The current on phase 1 is the highest, it could be simpler to fix $\alpha_{1}=0$, that is to say full-wave, but this is not the best solution as this duty cycle will be stuck to its lower limit. Consequently, a better solution consist in increasing the source current Is and for example, tune $\alpha=30^{\circ}$ on the phase that flows the highest current i.e. $\mathrm{I}_{1}\left(\right.$ so $\alpha_{1}=30^{\circ}$ ) that gives the opportunity to cancel all 3rd harmonics in the inverter currents and decrease the THD.

\section{EXPERIMENTAL RESULTS}

Fig. 18 shows the experimental and the simulated temperatures for the ten measurement points. Several tests were used to correlate simulations and experiments, which are in good agreement with each other.

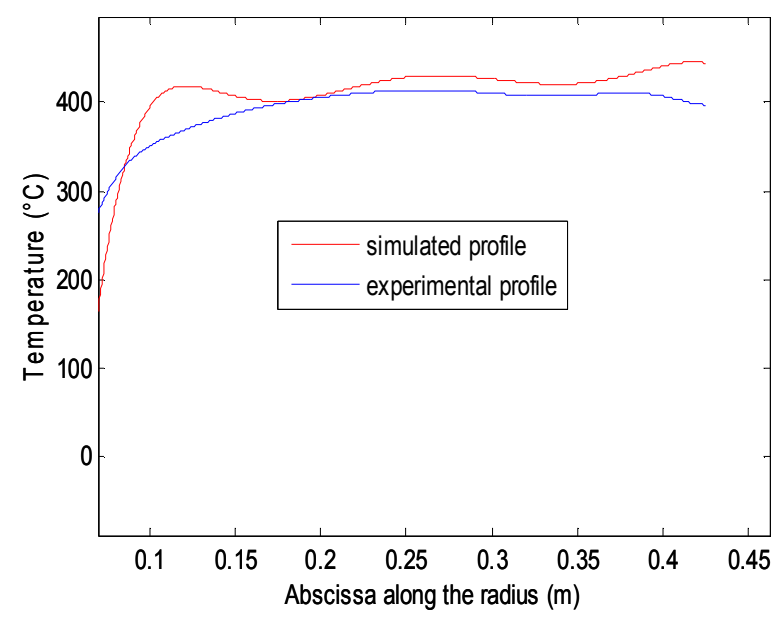

Fig. 18. Simulated and experimental profile

The differences between the simulations and experiments are quite acceptable because they are limited to $10 \%$ except in the centre of the disk where the model has to be improved and other experiments have to be run on the testbench.

\section{CONCLUSION}

This paper presents a simplified model that describes both the power electronics and the thermal behaviour of our induction heating system. The model has short computation time and provides satisfying results that are close to experimental results under the same conditions. It takes into account either convection, conduction or radiation. The sensitivity versus the capacitor values was put in evidence and an additional capacitor leads to a significant improvement. However, the model must be improved for better accuracy, especially in the centre of the disc where thermal conduction seems to be more important on the experimental profile. A first and simple control scheme only on the RMS currents, gave rather good performance and future works will include decoupling effects in the control loops and the control of the phase shifts between the inductor currents.

\section{ACKNOWLEDGMENT}

The authors would like to thank the $3^{\text {rd }}$ year ENSEEIHT students in Electrical Engineering and Control, Mrs S. ALLUIN, D. COSTES, A.GEISER, S. HAMOUMI, G. SANCHIS, C. THEPENIER and J. PETIT for their valuable participation in this work during their internships.

\section{REFERENCES}

[1] G. Manot, "Modélisation couplées des dispositifs électromagnétiques associés à des circuits d'électronique de puissance. Intégration de la commande des convertisseurs - Aide à la conception d'un dispositifs de chauffage par induction à flux transverse," PhD Thesis, Université de Toulouse, INP Toulouse, 2002.

[2] Uchida et al, Patent US 2005/199614, « Induction heating method and unit », December 2007

[3] C. Chaboudez, S. Khanniche, R. Glardon, D. Mari, J. Rappaz, et M. Swierkosz, "Numerical modeling in induction heating for axisymmetric geometries," Magnetics, IEEE Transactions on, 1997, p. 739 - 745.

[4] V. Labbé, "Modélisation numérique du chauffage par induction : approche éléments finis et calcul parallèle," Thèse de doctorat de l'Ecole des Mines de Paris, Apr. 2002.

[5] M. Souley, A. Spagnolo, O. Pateau, B. Paya, J.C. Hapiot, P. Ladoux, et P. Maussion, "Methodology to characterize the impedance matrix of multi-coil induction heating device," Electromagnetic Properties of Materials EPM, 2009,

[6] E. Rapoport, Y. Pleshivtseva, Optimal Control of Induction Heating Processes, Taylor \& Francis 2006, pp 19-25

[7] M. Souley, P. Maussion , P. Ladoux, O. Pateau, "Simplified model of a metal disc induction heating system" Heating by Electromagnetic sources, HES 2010 - Padua (Italy) May 19 - 21, 2010

[8] R. Sawant, N. Chame, et N. Rana, "A New Hybrid Power Control Technique for Induction Vessel Heating System," Industrial Technology, 2006. ICIT 2006, IEEE International Conference on, 2006, p. 1424-1429.

[9] H. Fujita, N. Uchida, K. Ozaki, PCC '07-Power Conversion Conference, Nagoya 2007April 2-5, pp 1498 - 1504 